\title{
Light-sensitive brain pathways and aging
}

V. Daneault ${ }^{1,2,3^{*}}$, M. Dumont ${ }^{2}$,É. Massé ${ }^{1,2}$, G. Vandewalle $e^{3,4}$ and J. Carrier ${ }^{1,2,3}$

\begin{abstract}
Notwithstanding its effects on the classical visual system allowing image formation, light acts upon several non-image-forming (NIF) functions including body temperature, hormonal secretions, sleep-wake cycle, alertness, and cognitive performance. Studies have shown that NIF functions are maximally sensitive to blue wavelengths (460-480 nm), in comparison to longer light wavelengths. Higher blue light sensitivity has been reported for melatonin suppression, pupillary constriction, vigilance, and performance improvement but also for modulation of cognitive brain functions. Studies investigating acute stimulating effects of light on brain activity during the execution of cognitive tasks have suggested that brain activations progress from subcortical regions involved in alertness, such as the thalamus, the hypothalamus, and the brainstem, before reaching cortical regions associated with the ongoing task. In the course of aging, lower blue light sensitivity of some NIF functions has been reported. Here, we first describe neural pathways underlying effects of light on NIF functions and we discuss eye and cerebral mechanisms associated with aging which may affect NIF light sensitivity. Thereafter, we report results of investigations on pupillary constriction and cognitive brain sensitivity to light in the course of aging. Whereas the impact of light on cognitive brain responses appears to decrease substantially, pupillary constriction seems to remain more intact over the lifespan. Altogether, these results demonstrate that aging research should take into account the diversity of the pathways underlying the effects of light on specific NIF functions which may explain their differences in light sensitivity.
\end{abstract}

Keywords: Light, Aging, Brain, Non-image-forming (NIF) functions

\section{Background}

Two functional systems detecting light: photoreceptor contribution and neural pathways

From a functional point of view, there are two systems detecting light in mammals and humans. The first one is the classical visual system responsible for image formation, and the second one is the nonimage-forming (NIF) system which detects environmental irradiance and contributes to modulation of many fundamental functions in living organisms. The physiological, behavioral, and cognitive functions which are modulated by light but not associated with conscious image perception are called NIF functions. These responses include circadian entrainment and shift the timing of circadian rhythms such as hormone secretion (melatonin, cortisol), heart rate, body

\footnotetext{
*Correspondence: veronique.daneault@gmail.com

'Functional Neuroimaging Unit, University of Montreal Geriatric Institute, Montreal, QC, Canada

${ }^{2}$ Center for Advanced Research in Sleep Medicine, Hôpital du Sacré-Cœur de Montréal, Montreal, QC, Canada

Full list of author information is available at the end of the article
}

temperature, and the sleep-wake cycle. These NIF effects are detected hours or days following light exposure. NIF responses also include acute physiological effects of light detected more rapidly, including melatonin suppression, pupillary constriction, alertness, and performance improvement as well as cognitive brain responses [1-5].

\section{Melanopsin retinal ganglion cells}

In the course of the year 2000s, the discovery of melanopsin (OPN4)-photosensitive pigment expressed by intrinsically photosensitive retinal ganglion cells (ipRGC) contributed to a better understanding of the neural bases of the NIF system [6]. The crucial importance of OPN4 in NIF responses has been corroborated by animal and human studies [7-10]. In humans, melanopsin is expressed in a small subset of cells representing only $1-2 \%$ of all retinal ganglion cells (RGC) [1, 10-14]. These photoreceptors measure the intensity of light (irradiance detection) with a maximum sensitivity toward short light wavelength (blue $~ 460-480 \mathrm{~nm}$ ) $[6,7,11]$. 
Melanopsin ipRGC have a low spatial resolution and long latencies as compared to cone and rod responses, and they show the ability to integrate photic energy over long periods of time $[6,7,13,14]$. To date, five ipRGC subtypes (M1-M5) have been identified according to morphological, molecular, and functional characteristics $[8,11,15]$. M1 have more melanopsin pigment than all other subtypes, and they can be subdivided according to the transcription factor Brn3b (Brn3b positive-M1 versus Brn3b-negative M1) [16-18]. M2 have extended dendrites and soma. M2 also shows more complex connections than M1 including afferents from the rods and cones suggesting that their intrinsic photic response might be more modulated by inputs from classical photoreceptors [18]. M3 has similar characteristics to M2, with intermediate levels of melanopsin $[15,19]$ and M4-M5 possess long dendrites, abundant arborization, and very low levels of melanopsin (i.e., low intrinsic light response) [15, 18-23]. M1 to M5 project to specific subcortical brain areas and play different functional roles in the NIF and in the classical visual systems $[16,22]$.

\section{Visual and non-visual neural pathways} Classical visual system: image forming system

Specific neural pathways are described for visual and non-visual systems (Fig. 1). Beginning with the eye, the classical visual system uses mainly rods and cones for image formation but also ipRGC for rudimentary visual functions [20, 22]. Cones are responsible for photopic vision (higher light intensity) with high spatial acuity and color discrimination. The classical photopic system in humans includes three types of cones showing mean peak sensitivity $\left(\lambda_{\max }\right)$ at 555 nanometers $(\mathrm{nm})$, i.e., the green part of the light visible spectrum. S-cones express the short-wavelength-sensitive opsin cyanolabe $\left(\lambda_{\max }\right.$ $420 \mathrm{~nm}), \quad M$-cones express chlorolabe opsin $\left(\lambda_{\max }\right.$ $535 \mathrm{~nm}$ ), and L-cones express a red-shifted opsin, the erythrolabe $\left(\lambda_{\max } 565 \mathrm{~nm}\right)$ [24]. Scotopic vision (i.e., contrast detection, dim light vision) is sustained by rods [25] using rhodopsin photopigment $\left(\lambda_{\max } 507 \mathrm{~nm}\right.$ in humans) [24]. Using the optic tract, the brain pathways of the classical visual system project to subcortical nucleus, such as the thalamic lateral geniculate nucleus (LGN), the superior colliculus (SC), and the lateral

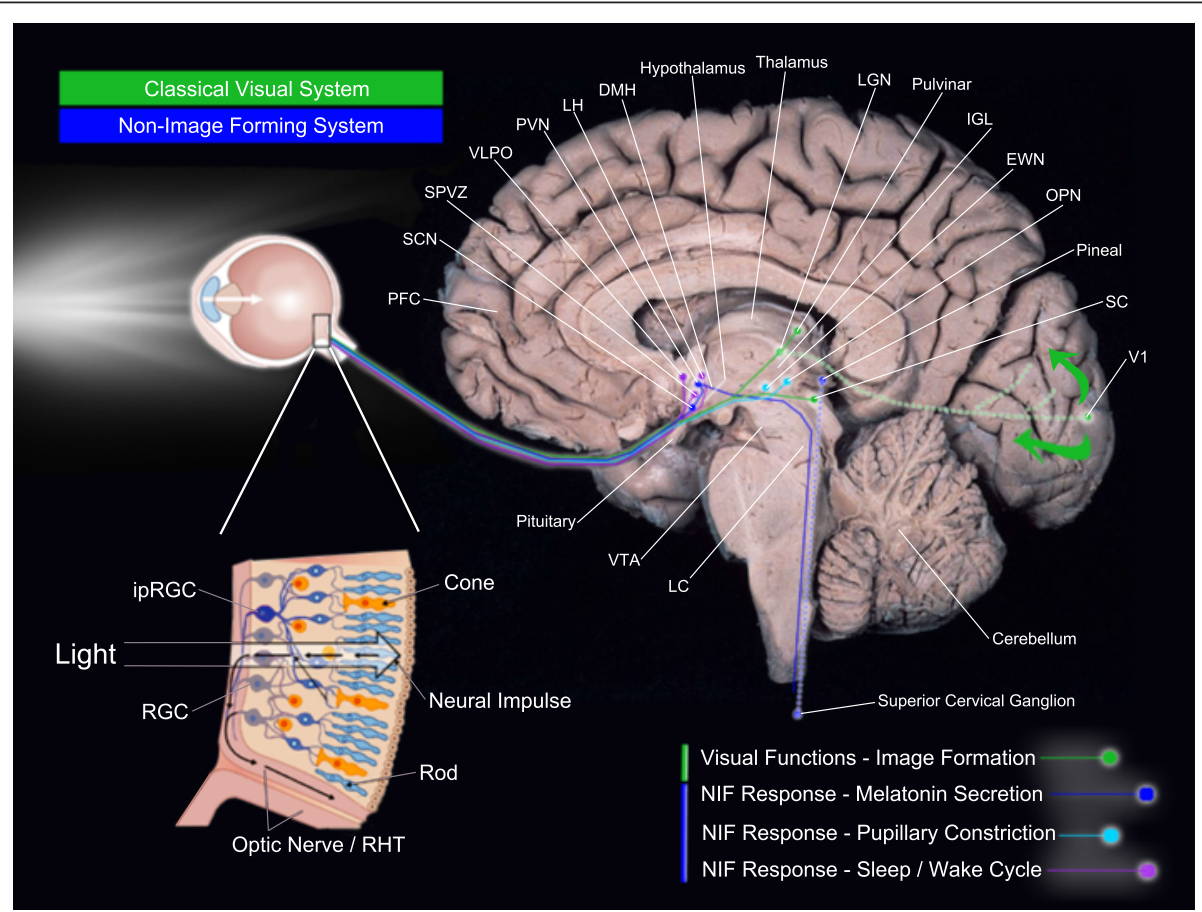

Fig. 1 Light-sensitive brain pathways. Simplified brain networks (not exhaustive representation) of the classical visual system and the non-image-forming system. Abbreviations: PFC prefrontal cortex, SCN suprachiasmatic nucleus, SPVZ subparaventricular zone, VLPO ventrolateral preoptic nucleus, PVN paraventricular nucleus of the hypothalamus, LH lateral hypothalamus, DMH dorsomedial nucleus of the hypothalamus, LGN lateral geniculate nucleus, IGL intergeniculate leaflet, EWN Edinger-Westphal nucleus, OPN olivary pretectal nucleus, SC superior colliculus, V1 primary visual area, LC locus coeruleus, VTA ventral tegmental area, ipRGC intrinsically photosensitive retinal ganglion cell, RHT retino-hypothalamic tract. Eye illustration components modified from: http://2012books.lardbucket.org/books/beginning-psychology/s08-02seeing.html —reproduction/modifications in accordance with: http://creativecommons.org/licenses/by-nc-sa/3.0/ Brain template: reproduced with permission from McGraw-Hill Education Material (source: Saladin, Kenneth S., Human Anatomy, Edition: 2, ISBN: 9780072943689, Figure 15.2-b, p. 425) 
posterior pulvinar complex (Pul-LP), before reaching the primary visual occipital area (V1) and then at other neocortical regions engaged in dorsal and ventral visual attentional brain pathways [26-29] (Fig. 1). Animal studies show that ipRGC (possibly non-M1 subtypes [22, 23]) also send projections to dorsal LGN (dLGN) and SC [16, $17,22,23,30,31]$. These ipRGC projections play a role in conscious perception of spatial brightness and speed motion [16, 31-33]. Recent animal evidences also support the functional role of melanopsin-expressing ipRGC projections to dLGN in visual responses optimization with irradiance detection [33]. Overall, complex interactions between classical (cones, rods) and non-classical (melanopsin-expressing ipRGC) photoreceptors and their projections contribute to the classical visual system $[16,17,20,32]$.

\section{Non-visual system/non-image-forming system}

The second system, namely, the NIF system, uses ipRGC in addition to rods and cones and shows a peak sensitivity in the blue part of the light spectrum $(\sim 460-480 \mathrm{~nm})$ $[6,7,11,13,14,31,34]$. A monosynaptic pathway, the retinohypothalamic tract (RHT), conveys light information from ipRGC axons [35, 36]. As illustrated in Fig. 1, the NIF system directly projects via the RHT to subcortical regions engaged in melatonin secretion, pupillary constriction, and the regulation of the sleepwake cycle $[2,37,38]$.

RHT directly connects the ipRGC from the retina to the suprachiasmatic nuclei $(\mathrm{SCN})$ of the anterior hypothalamus, the master circadian oscillator (biological clock) $[1,11,39] . \mathrm{SCN}$ is the endogenous master biological clock that allows temporal organization of living organisms, synchronizing circadian rhythms among themselves as well as with the external environment. SCN sends efferent projections to the hypothalamic and non-hypothalamic structures [30], including the paraventricular nucleus of the hypothalamus (PVN), the dorsomedial nucleus of the hypothalamus (DMH), and finally, the intergeniculate leaflet (IGL) of the thalamus which also sends projections to SCN [40]. Interactions between the SCN, the PVN, the superior cervical ganglion (SCG), and the pineal gland support the neural network of melatonin suppression [41] (see Fig. 1 melatonin suppression). Without being exhaustive here, many brain areas other than the SCN also receive direct projections from the ipRGC. Thus, olivary pretectal nucleus (OPN), the crucial node of the pupillary constriction pathway, receives direct projections from the ipRGC. OPN sends projections to the Edinger-Westphal nucleus (EWN) which in turn, innervate the sphincter muscle of the pupil allowing pupillary constriction [42]. The ipRGC also sends direct connections to regions engaged in the regulation of the sleep-wake cycle $[2,37,38]$, such as the ventrolateral preoptic nucleus (VLPO; sleepwake regulation core-region), the subparaventricular nucleus/zone (SPVZ) of the hypothalamus, which is involved in sleep regulation but also in motor activity, as well as the lateral hypothalamus ( $\mathrm{LH})$, which contains orexin (hypocretin) neurons regulating wakefulness [20, 22, 30, 40]. Furthermore, light may also affect the sleep-wake cycle via the connections between the SCN and the DMH since the DMH also sends projections to the VLPO, the $\mathrm{LH}$, and the locus coeruleus (LC) $[40,43,44]$. The amygdala, a structure involved in emotional processes, also receives direct projections from the ipRGC $[30,31]$ and might represent a key target of the NIF system by potentiating effects of light on alertness and mood. This limbic area is part of the neural network named the "Salience Network" associated with responsiveness to stimuli [45].

\section{Photoreceptor contribution to NIF responses}

Light stimulus characteristics influence the photoreceptor's contribution to specific NIF responses. For instance, light intensity, wavelength, and temporal characteristics define the specific photoreceptor's contribution to pupil light reflex (PLR) [46-49]. At low light intensities, rods and cones contribute to PLR but cones' contribution decreases as the duration of light exposure increases and is minimal beyond $30 \mathrm{~s}[47,48]$. At high light intensities ( $>12 \log$ units per $\mathrm{ph} / \mathrm{cm}^{2} / \mathrm{s}$ ), ipRGC mainly contributes to the sustained PLR $[8,47,50]$, i.e., in response to light exposure extending beyond $30 \mathrm{~s}$.

Recently, complex photoreceptor interventions/communications have also been reported for circadian entrainment. Blue-yellow cone's color discrimination/ opponency seem to modulate the ipRGC signal transmission to SCN neurons making them sensitive to color [51]. Thus, SCN cells would be sensitive to both brightness and color. This could correspond to an evolutionary strategy using color as a time-of-day indicator based on spectral composition of the solar cycle and twilight transition [51].

Studies have reported that $80 \%$ of all ipRGC projections to the SCN are from M1 Brn3b-negative and $20 \%$ are from M2 [21, 52]. In contrast, $45 \%$ of ipRGC projections to the OPN (pupillary constriction) are from M1 Brn3b-positive (shell part) and $55 \%$ are from M2 subtype (core part) [10, 21, 52]. Relative contribution of each photoreceptor and interactions still need to be determined for specific NIF functions [2, 10, 23]. The classical visual system and the NIF system are different by their respective functions but evidences now reveal that a complete dichotomy of these two systems is outdated at the eye and brain levels. An integrative hypothesis suggesting a multi-dimensional system with a relative segregation of different networks, rather than their full 
independence, seems more likely based on the observed data. Further research will help identify retinal and neural networks involved in the effects of light for each NIF functions.

Overall, as for the classical visual pathway, the underlying neural pathways of the NIF system are complex and several brain areas are involved in the mechanisms by which changes in the quality of the light environment affect various NIF functions [22, 30, 31].

\section{Effects of light on alertness and cognitive functions: short versus longer wavelengths}

In agreement with the peak sensitivity of each lightdetecting system, many studies have confirmed greater sensitivity of non-visual responses under blue monochromatic light exposure ( 460-480 $\mathrm{nm})$, in comparison to longer wavelengths such as green monochromatic light $[4,5,53-59]$. Hence, the impact of light on sleepiness, alertness, performance, as well as the modulation of cognitive brain functions are greater under blue monochromatic light and blue-enriched light exposure, as compared to longer light wavelengths $[4,5,53-57,60]$. Lower levels of subjective sleepiness [53,61,62], but also of objective alertness as measured with electroencephalogram (EEG), are reported under blue light exposure, as compared to longer light wavelength or darkness [53]. Higher performance speed to the psychomotor vigilance task (PVT) is also observed when exposed to blue-enriched light exposure as compared to longerenriched lights $[4,63,64]$. Likewise, blue monochromatic light exposure, as compared to green and red monochromatic lights, induces higher amplitude levels on the P300, an event-related potential associated with attentional demands [65].

Since 2004, a number of studies investigated the brain mechanisms underlying the stimulating effects of light on alertness and cognitive functions in humans [5, 56, 57, 66-72]. These investigations showed that light exposure, particularly blue light, during the execution of cognitive tasks potentiate brain activations of subcortical structures associated with vigilance including the hypothalamus, brainstem (LC), thalamus, and limbic areas (the amygdala and hippocampus) likely before spreading to cortical regions engaged in the ongoing task [5]. Recently and according to a theory of melanopsin bistable properties $[59,73,74]$, long wavelength light exposure $(589 \mathrm{~nm})$ administered an hour before a given test light exposure increases the impact of that test light on some brain responses (i.e., pulvinar, cerebellum, frontal areas) associated with the execution of a cognitive task [75]. Overall, these studies confirmed that in young subjects, light exposure, particularly blue light, has greater modulating effects on cognitive brain functions than other light wavelengths most likely through melanopsin photoreception and triggers brain activation increases in regions related to alertness and to executive functions (for a review, see $[5,76]$ ).

\section{Aging and non-image-forming system modifications}

Age-related differences in the impact of light have been reported for some acute non-visual responses, with a decreased effect of monochromatic blue light ( $456 \mathrm{~nm}$ ) on clock gene expression, subjective alertness, sleepiness, and mood in older, as compared to young individuals [77-79]. However, some investigations did not find age-related reduction in the impact of light when using polychromatic white light [80-82]. A potential decrease in the impact of light remains therefore debated, and it could be that age-related changes occur for specific wavelengths of light or for specific NIF responses but not for others.

Age-related modifications from the eye to the brain may affect the NIF system and contribute to lower sensitivity to light in aging [83-89]. Circadian oscillations are driven by rhythmic expression of clock genes and autoregulatory transcriptional-translational feedback loops over approximately a $24-\mathrm{h}$ period. Aging appears to be associated with changes in clock gene expression with a reduced amplitude in Bmal1 and Clock expression in SCN [90-92], lower Per2 expression in the pituitary gland [93], and lower Per 1,2,3 expression at the peripheral level (liver, heart) [94]. Age-related differences under light exposure were also revealed including reduction in Per1 expression after light pulses [90-92] and reduction of Per2 expression following blue morning light exposure [79]. Since Per 1-2 expression is rapidly induced by light and is required for entrainment, age-related temporal disorganization may partly result from lower SCN sensitivity to photic stimulation (for a review, see [95]).

Age-related modifications among other molecular and neuronal factors might also contribute to decrease sensitivity to light. Several studies have reported age-related changes in the rhythmic synthesis, release, and expression of vasoactive intestinal polypeptide (VIP) and arginine vasopressine (AVP), two important neuropeptides expressed in the SCN [95-102]. These changes might affect the precision and robustness of rhythmic information transmission by the SCN to other neural sites and might contribute to attenuated photic input signal of the circadian timing system in aging [99, 100, 102, 103]. Other alterations such as a reduction in gray and white matter and changes in vascularization of the brain might contribute to age-related modifications of the NIF system [104-107]. Specifically, decrease density of norepinephrine (NE) neurons in the LC [108], SCN deficits in membrane properties and GABAergic postsynaptic current amplitude [88], and hypertrophy of astrocytes and microglia in SCN (responsible for glutamate 
uptake-the main neurotransmitter of the RHT) [109] have been reported. Again, all these modifications might induce functional deficits among various systems including the non-image-forming one.

Last but not least, many important age-related changes also occur at the eye level: there is a decrease of photoreceptor sensitivity, a reduction in pupil size, known as senile miosis, and an increase of ocular crystalline lens absorption known as "lens yellowing" [85, 86, 110-115]. The combination of all these changes is very likely to reduce the amount of light reaching the retina and may modulate the impact of light on NIF functions.

\section{Pupillary constriction and brain sensitivity to light in the course of aging}

In order to improve the understanding of the impact of light on non-visual older subjects, we completed two research protocols. We aimed at measuring pupillary constriction [116] and non-visual cognitive brain activity while exposed to light [117]. We recruited two groups of subjects, 16 young and 14 older individuals (see [116] and [117] for complete sample description). All were healthy, right handed, non-smokers, slept between 7 and $9 \mathrm{~h}$ per night, were non-medicated, and MRI compatible. They also underwent an optometric exam to make sure they were free of ocular disease. The main hypothesis of our investigations was that in older, compared to young subjects, we would detect a reduction in pupillary and brain responses to light.

\section{Pupillary constriction in relation with healthy aging}

In the pupillometry protocol, subjects were first maintained in darkness for 15 min before we captured baseline pupil size. Subjects were then exposed for $45 \mathrm{~s}$ to three irradiances levels of blue $(480 \mathrm{~nm})$ and green $(550 \mathrm{~nm})$ monochromatic light (low $7 \times 10^{12} \mathrm{ph} / \mathrm{cm}^{2} / \mathrm{s}$, medium $3 \times$
$10^{13} \mathrm{ph} / \mathrm{cm}^{2} / \mathrm{s}$, high $1 \times 10^{14} \mathrm{ph} / \mathrm{cm}^{2} / \mathrm{s}$ ). Resting period in darkness lasted 2 min between each light exposure.

As expected, at the baseline (before any light exposure), analysis of the raw pupil size area showed that older subjects have a smaller pupil as compared to young subjects [116]. As PLR was the NIF response of interest, we subsequently estimated the sustained pupillary constriction for each age group under each light condition. Normalized pupillary constriction was calculated for each subject using the value under light exposure in relation with the baseline pupil size. As illustrated in Fig. 2, results showed that pupillary constriction was greater with blue than green light and greater at higher irradiance. However, analysis did not reveal significant age-related differences for sustained pupillary constriction. Our results concur with senile miosis, as absolute pupil size was smaller with age. According to the peak sensitivity of the NIF system, we also observed greater effects of blue rather than green lights and higher rather than lower irradiances. However, similar sustained pupillary constriction was observed in both age groups suggesting that despite a reduction of the amount of light reaching the retina, this non-visual response to light is maintained in healthy aging.

Our first study confirms the reduction in pupil size with aging and the greater impact of blue versus. green light on PLR [116] but does not reveal significant agerelated differences in pupil dynamic under light exposure. This original result indicates that PLR might differ from other acute non-visual responses showing a decrease in sensitivity to blue light with age (i.e., suppression of melatonin secretion, modulation subjective alertness, mood and the expression of certain clock genes) [77-79].

As previously exposed, different NIF responses are regulated by partially independent neural networks

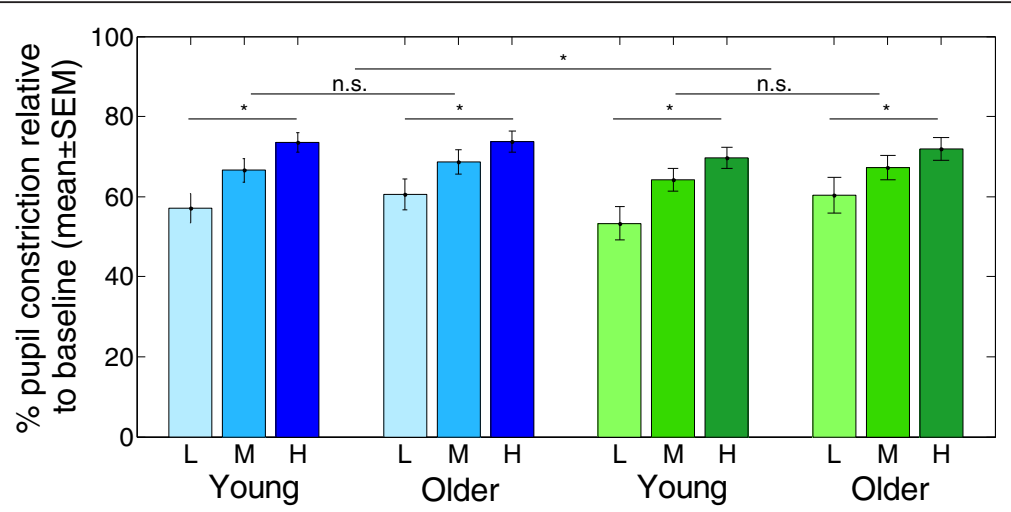

Fig. 2 Steady-state pupil constriction in young and older individuals. Mean pupillary constriction relative to baseline \pm SEM in each age group. Blue bars: blue light at low $(L)$, medium $(M)$, and high $(H)$ irradiances. Green bars: green light at low $(L)$, medium $(M)$, and high $(H)$ irradiances. Effects of wavelength and irradiance levels were significant $\left({ }^{*} p<0.05\right)$, but there was no difference between age groups and no interaction with age (n.s. not significant). Reproduced with permission from [116] 
[23, 30, 118-120]. These anatomical differences support the possibility of variations in the age-related changes in effects of light on various NIF functions, sustained for instance by the OPN (PLR) or the SCN (entrainment). Specific light sensitivities for different NIF responses $[121,122]$ might also contribute to the diversity in the changes in the impact of light in aging. Animal evidences revealed indeed higher sensitivity thresholds (i.e., requiring higher light level) for the circadian entrainment phase response and masking (i.e., motor activity suppression in nocturnal animals under light exposure) than for pupillary constriction [121, 122]. It is plausible that the sensitivity threshold of the pupillary reflex is low enough to trigger a pupillary response similar to that of young people despite the reduction of photic input reaching the retina.

\section{Brain sensitivity to light, cognition, and healthy aging}

For the neuroimaging study, the same two groups of subjects completed an fMRI recording at night, $1 \mathrm{~h}$ after their habitual sleep time. They had to follow a regular sleep schedule 7 days prior to the experiment and were maintained in darkness $2 \mathrm{~h}$ before the experimental light exposure. In the scanner, subjects completed 28 blocks of $45 \mathrm{~s}$ of the auditory working memory two-back task while maintained in a darkness condition or under blue monochromatic light of three irradiance levels (low $7 \times$ $10^{12} \mathrm{ph} / \mathrm{cm}^{2} / \mathrm{s}$, medium $3 \times 10^{13} \mathrm{ph} / \mathrm{cm}^{2} / \mathrm{s}$, high $1 \times$ $\left.10^{14} \mathrm{ph} / \mathrm{cm}^{2} / \mathrm{s}\right)$. The two-back task required the subjects to answer, with a response box, whether each letter presented was the same as the two prior letters. This task engaged auditory processing, attention, storing, comparing, and updating information in working memory [123]. Subjects were well trained to the task prior to the fMRI recordings. Consequently, behavioral analyses revealed no significant differences between the two groups and between the four light conditions for accuracy and response time values [117]. This was intended and consistent with a ceiling effect in both groups, so that the limited amount of light we administered could not significantly impact performance. This situation was ideal for the purpose of our study which was to investigate
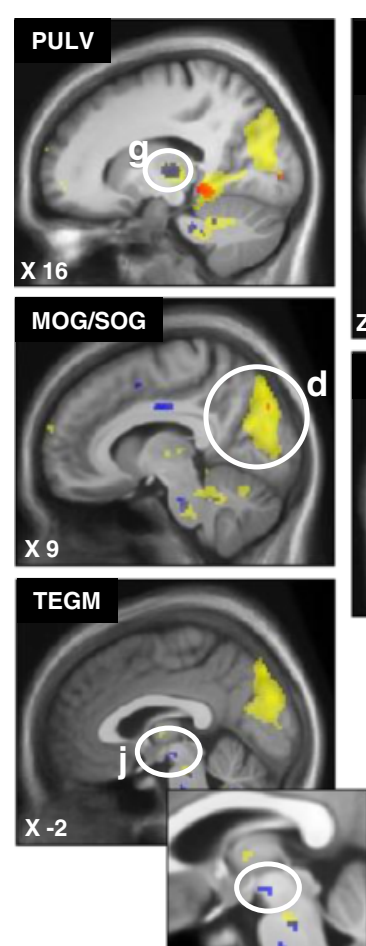
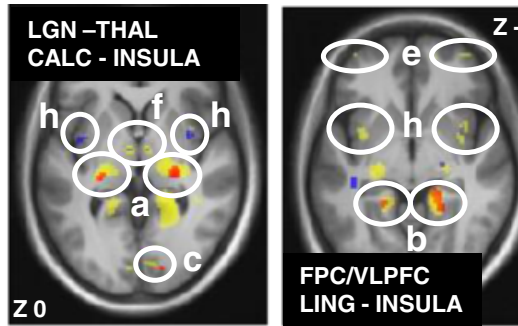

\section{LING - INSULA}
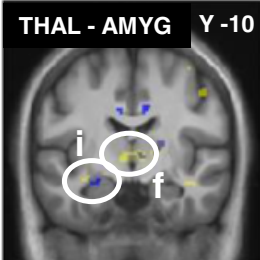

$\square$ YOUNGER (Y) OLDER (O) $\mathrm{Y}>\mathrm{O}$
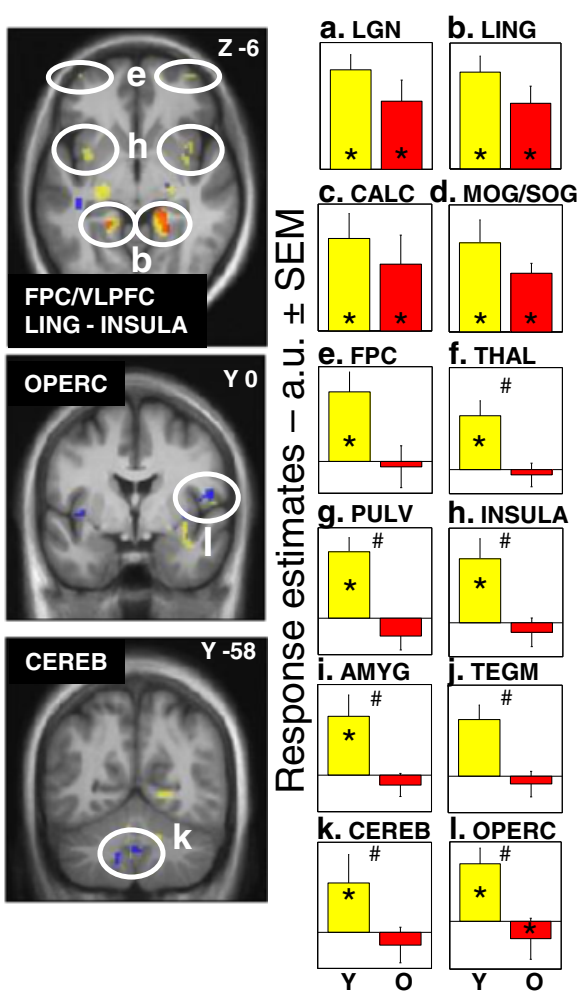

Fig. 3 Effect of the presence of light on brain responses of younger and older individuals performing an auditory two-back task. Statistical results ( $p<0.001$ uncorrected) overlaid over the mean structural image of all participants. Significant responses to light are displayed in yellow for younger individuals $(Y$ ), in red for older individuals $(O)$, whereas group differences $(Y>0)$ are in blue. Right panels a-I show activity estimates (arbitrary unit (a.u.) \pm standard error of the mean) in each brain region. *Significantly activated, $p<0.05$ corrected for multiple comparisons over small volumes of interest; \# significant group differences, $p<0.05$ corrected for multiple comparisons over small volumes of interest. Abbreviations: a $L G N$ lateral geniculate nucleus, b LING lingual gyrus, c CALC calcarine sulcus, d MOG/SOG middle and superior occipital gyrus, e FPC frontopolar cortex, f THAL dorsomedian thalamus, $\mathbf{g}$ PULV thalamus pulvinar, h INSULA insula, i AMYG amygdala, j TEGM tegmentum, k CEREB cerebellum, I OPERC frontal operculum. Please refer to Table 2 of [113] for brain clusters coordinates. Reproduced with permission from [117] 
the brain mechanisms involved in the impact of light as we are sure that behavior did not significantly bias our fMRI results.

In accordance with literature, and supporting that the subjects performed the task correctly, we first showed brain activations in areas known to be involved in the task including the frontal gyrus, the superior parietal and temporal gyrus, the intraparietal sulcus (IPS), the motor and sensorimotor cortices as well as the thalamus, and the cerebellum [117]. We also investigated which brain areas responded to the presence of light during the execution of the task, independently of the irradiance levels, in young and older subjects. Results indicated common brain activations in young and older individuals in the LGN, the lingual gyrus, the calcarine sulcus, and in the occipital gyrus. These common brain activations in relation with the effects of light are presented in Fig. 3.
Analysis also revealed significant age-related differences as young subjects presented a higher impact of light than older subjects (represented in blue in Fig. 3) in the thalamus and a region compatible with the ventral tegmental area (VTA), important areas for arousal regulation [124], in the amygdala and the insular cortex, regions involved in emotional regulation [125], as well as in the frontal operculum and in the cerebellum. Some of these regions have been previously reported in nonvisual effects of light in young subjects and are part of the salience brain network engaged in the selection of most relevant information to guide behavior $[45,126]$. Less brain sensitivity to light among regions of this network might have important impacts on brain sensitivity to light in aging on alertness and attention.

We also investigated which brain areas responded differently with age to increasing blue light irradiance levels during the ongoing cognitive task. Again, results showed
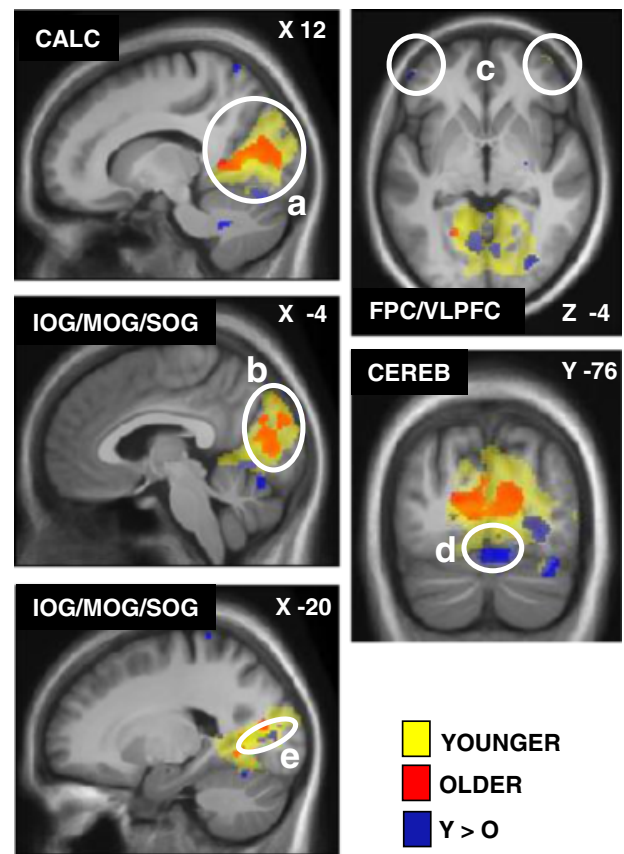

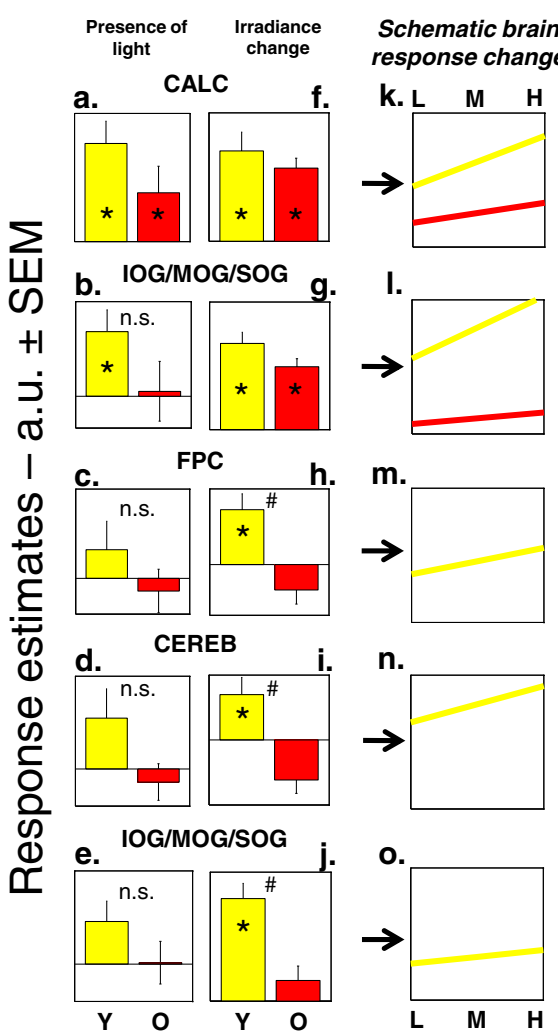

Fig. 4 Effect of irradiance level of light on brain responses of younger and older individuals performing an auditory two-back task. Statistical results ( $p<0.001$ uncorrected) overlaid over the mean structural image of all participants. Significant changes in responses as a function of irradiance level are displayed in yellow for younger individuals $(Y$ ) and in red for older individuals $(O)$, whereas group differences $(Y>0)$ are in blue. Panels a-e represent estimates [a.u. \pm standard error of the mean (SEM)] of the brain responses while exposed to blue light independent of the irradiance change. Panels $\mathbf{f}-\mathbf{j}$ represent estimates (a.u. \pm SEM) of the linear change in brain responses with change in irradiance level. Panels $\mathbf{k}-\mathbf{o}$ consist of a schematic representation of the composite of both components (responses to light and irradiance change) showing the evolution of the responses with change in irradiance level. Panels $\mathbf{m}$-o only includes younger individuals because responses were not significantly affected by irradiance change in older individuals in the brain regions considered. *Significantly activated, $p<0.05$ corrected for multiple comparisons over small volumes of interest; " significant group differences, $p<0.05$ corrected for multiple comparisons over small volumes of interest; $n$.s. non significant group difference. Abbreviations: a \& f CALC calcarine sulcus, b, e, g, \& j IOG/MOG/SOG inferior/middle/superior occipital gyrus, c \& h FPC frontopolar cortex, d \& i CEREB cerebellum. Please refer to Table 3 of [113] for brain clusters coordinates. Reproduced with permission from [117] 
common brain activations in young and older subjects in the calcarine sulcus, as well as in the inferior, median, and superior occipital gyrus. As represented in Fig. 4, these regions seem to increase their activation with increased light intensity in both groups. More importantly, our results also pointed toward age-related differences in the prefrontal cortex, an important region for higher cognitive functions [127], in the occipital cortex, a region related to the visual system, and finally, in the cerebellum. Our results suggested an increase in frontal, occipital, and cerebellum brain activations in young subjects following light increase intensity, while in older subjects, this phenomenon was absent.

Overall, these results indicated that light is still able to modify ongoing brain activity in older individuals in the context of our protocol. Age-related modifications are also evident at the irradiance levels we used. Based on our results, one could argue that light impact is better conserved in aging in brain areas that are typically associated with vision (LGN, calcarine sulcus, and occipital areas), while areas involved in alertness and cognition regulation seem to undergo a more pronounced diminution in their response to light.

Reduced age-related effects of blue monochromatic light on the thalamus and VTA activity might be related to various molecular and neural changes in the arousal system. Hypocretin/orexin neurons, the expression of which decreases with age [128], innervate many cell groups including "wake-active" monoaminergic populations of the VTA [129-132]. A reduced impact of blue monochromatic light in the VTA-compatible area suggests that the dopaminergic system could be involved in age-related changes of the stimulating effect of light on brain responses. The VTA is an important source of dopamine in the brain and is crucial both for the regulation of sleep and alertness and for cognition and mood [124]. It is notable that the VTA sends projections to the SCN [133]. Since dopamine dysfunction is thought to play an important role in the cognitive decline found in healthy aging [134], the reduced effect of light upon brain-related dopamine regions might contribute to reduce the stimulating effect of blue light on cognitive functions.

\section{Conclusions}

\section{Lighting-up the aging brain}

Light is a simple mean that could easily be used to improve cognition, sleepiness, mood, and sleep in normal and pathological aging. Daytime sleepiness is a significant characteristic of specific neurodegenerative disorders and is associated with not only current cognitive impairments but also increased risks for developing cognitive decline [135-141]. In Alzheimer's and Parkinson's disease patients, excessive sleepiness and fatigue have been associated with increased functional impairment [142] and cognitive dysfunction [143]. While Parkinson's disease is directly related to dopamine dysfunction [144], a slow degeneration of hypocretin neurons has been reported over the course of Alzheimer's disease [130]. Importantly, light exposure has a positive effect on sleep and mood in Parkinson's disease patients and improvement of cognitive functions have been reported using $2 \mathrm{~h}$ of bright light therapy (polychromatic light $-3000 \mathrm{~lx}$ and over) in Alzheimer's disease patients [145, 146]. Qualitative positive effects of light exposure on sleep, mood, and cognition have also been reported in Alzheimer's disease patients with greater effect of blue-green bright light exposure in the morning as compared to dim red light [147].

The spectral quality of light may be a crucial factor to consider when dealing with light in aging. Besides monochromatic light, one could use polychromatic light, enriched in blue wavelength for instance. These would be more applicable to real life and have been reported to improve some aspects of cognitive performance relative to classical incandescent light [64, 148]. Each non-visual response to light will require special attention as they may be differently affected by age since they rely in part on different photoreceptor contributions and partly independent brain pathways.

Furthermore, investigations need to identify light characteristics (quality, quantity, duration) that can effectively modulate alertness and cognitive performance in aging. In order to reach a better understanding of the eye factors upon brain sensitivity to light, future investigations need to measure pupil size at the time of the experience or to include older subjects who underwent lens replacement following a cataract surgery. As it is now recognized that melanopsin gene polymorphism (OPN4) influences pupil size under light exposure $[149,150]$ and that clock gene polymorphism (PER3) influences non-visual sensitivity to light according to sleep pressure and circadian phase $[57,63,75]$, it is also crucial to consider genetic$\mathrm{s}$-age interactions. Aside from pharmacology, we may then be in a position to provide light tools to improve life quality in aging.

\section{Ethics approval and consent to participate}

Our experiments received Institutional ethics approval from the Research ethics board of the Comite mixte d'éthique de la recherche du Regroupement Neuroimagerie Québec (CMER-RNQ) and written informed consent was obtained from each participant.

Competing interests

The authors declare that they have no competing interests. 


\section{Authors' contributions}

$J C, G V$, and MD had the original idea for the studies. EM and VD created Fig. 1. VD drafted the manuscript, which was revised by all authors. All authors read and approved the final manuscript.

\section{Acknowledgements}

Work was performed at University of Montreal Geriatric Institute, Montreal, Quebec, Canada. The authors thank André Cyr and Carollyn Hurst for their help with data collection. We also thank Jean Paquet from the Center for Advanced Research in Sleep Medicine, Hôpital du Sacré-Coeur de Montréal, for his support on the statistical analyses

\section{Funding}

This was not an industry-supported study. Our work was funded by the Canadian Institutes of Health Research (CIHR), Natural Sciences and Engineering Research Council of Canada (NSERC), Fonds de la recherche du QuébecSanté (FRQS), and by the International Office of the University of Montreal.

\section{Author details}

${ }^{1}$ Functional Neuroimaging Unit, University of Montreal Geriatric Institute, Montreal, QC, Canada. ${ }^{2}$ Center for Advanced Research in Sleep Medicine, Hôpital du Sacré-Cœur de Montréal, Montreal, QC, Canada. ${ }^{3}$ Department of Psychology, University of Montreal, Montreal, QC, Canada. ${ }^{4}$ Cyclotron Research Centre, University of Liège, Liège, Belgium.

\section{Received: 8 January 2016 Accepted: 1 March 2016}

\section{Published online: 15 March 2016}

\section{References}

1. Hankins MW, Peirson SN, Foster RG. Melanopsin: an exciting photopigment. Trends Neurosci. 2008;31(1):27-36.

2. Altimus CM, Guler AD, Villa KL, McNeill DS, Legates TA, Hattar S. Rods-cones and melanopsin detect light and dark to modulate sleep independent of image formation. Proc Natl Acad Sci U S A. 2008;105(50):19998-20003.

3. Leary SM, Gilpin P, Lockley L, Rodriguez L, Jarrett L, Stevenson VL. Intrathecal baclofen therapy improves functional intelligibility of speech in cerebral palsy. Clin Rehabil. 2006:20(3):228-31.

4. Chellappa SL, Steiner R, Blattner P, Oelhafen P, Gotz T, Cajochen C. Nonvisual effects of light on melatonin, alertness and cognitive performance: can blue-enriched light keep us alert? PLoS One. 2011;6(1):e16429.

5. Vandewalle G, Maquet P, Dijk DJ. Light as a modulator of cognitive brain function. Trends Cogn Sci. 2009;13(10):429-38.

6. Provencio I, Rodriguez IR, Jiang G, Hayes WP, Moreira EF, Rollag MD. A novel human opsin in the inner retina. J Neurosci. 2000;20(2):600-5.

7. Panda S, Sato TK, Castrucci AM, Rollag MD, DeGrip WJ, Hogenesch JB, Provencio I, Kay SA. Melanopsin (Opn4) requirement for normal lightinduced circadian phase shifting. Science. 2002;298(5601):2213-6.

8. Lucas RJ, Hattar S, Takao M, Berson DM, Foster RG, Yau KW. Diminished pupillary light reflex at high irradiances in melanopsin-knockout mice. Science. 2003:299(5604):245-7.

9. Ruby NF, Brennan TJ, Xie X, Cao V, Franken P, Heller HC, O'Hara BF. Role of melanopsin in circadian responses to light. Science. 2002;298(5601):2211-3.

10. Guler AD, Ecker JL, Lall GS, Haq S, Altimus CM, Liao HW, Barnard AR, Cahill H, Badea TC, Zhao H, Hankins MW, Berson DM Lucas RJ, et al. Melanopsin cells are the principal conduits for rod-cone input to non-image-forming vision. Nature. 2008;453(7191):102-5.

11. Berson DM. Strange vision: ganglion cells as circadian photoreceptors. Trends Neurosci. 2003;26(6):314-20.

12. Hankins MW, Lucas RJ. The primary visual pathway in humans is regulated according to long-term light exposure through the action of a nonclassical photopigment. Curr Biol. 2002;12(3):191-8.

13. Hattar S, Liao HW, Takao M, Berson DM, Yau KW. Melanopsin-containing retinal ganglion cells: architecture, projections, and intrinsic photosensitivity. Science. 2002;295(5557):1065-70

14. Berson DM, Dunn FA, Takao M. Phototransduction by retinal ganglion cells that set the circadian clock. Science. 2002;295(5557):1070-3.

15. Sand A, Schmidt TM, Kofuji P. Diverse types of ganglion cell photoreceptors in the mammalian retina. Prog Retin Eye Res. 2012;31(4):287-302.

16. Zhao X, Stafford BK, Godin AL, King WM, Wong KY. Photoresponse diversity among the five types of intrinsically photosensitive retinal ganglion cells. J Physiol. 2014;592(Pt 7):1619-36.
17. Brown TM, Gias C, Hatori M, Keding SR, Semo M, Coffey PJ, Gigg J, Piggins HD, Panda S, Lucas RJ. Melanopsin contributions to irradiance coding in the thalamo-cortical visual system. PLoS Biol. 2010;8(12):e1000558.

18. Sexton T, Buhr E, Van Gelder RN. Melanopsin and mechanisms of non-visual ocular photoreception. J Biol Chem. 2012;287(3):1649-56.

19. Munch M, Kawasaki A. Intrinsically photosensitive retinal ganglion cells: classification, function and clinical implications. Curr Opin Neurol. 2013;26(1):45-51.

20. Schmidt TM, Chen SK, Hattar S. Intrinsically photosensitive retinal ganglion cells: many subtypes, diverse functions. Trends Neurosci. 2011;34(11):572-80.

21. Baver SB, Pickard GE, Sollars PJ. Two types of melanopsin retinal ganglion cell differentially innervate the hypothalamic suprachiasmatic nucleus and the olivary pretectal nucleus. Eur J Neurosci. 2008;27(7):1763-70.

22. Ecker JL, Dumitrescu ON, Wong KY, Alam NM, Chen SK, LeGates T, Renna JM, Prusky GT, Berson DM, Hattar S. Melanopsin-expressing retinal ganglioncell photoreceptors: cellular diversity and role in pattern vision. Neuron. 2010:67(1):49-60.

23. Schmidt TM, Do MT, Dacey D, Lucas R, Hattar S, Matynia A. Melanopsinpositive intrinsically photosensitive retinal ganglion cells: from form to function. J Neurosci. 2011;31(45):16094-101.

24. Lucas RJ, Peirson SN, Berson DM, Brown TM, Cooper HM, Czeisler CA Figueiro MG, Gamlin DP, Lockley SW, O'Hagan JB, Price LL, Provencio I, Skene DJ, et al. Measuring and using light in the melanopsin age. Trends Neurosci. 2014;37(1):1-9.

25. Kefalov VJ. Rod and cone visual pigments and phototransduction through pharmacological, genetic, and physiological approaches. J Biol Chem. 2012; 287(3):1635-41.

26. Panetsos F, Sanchez-Jimenez A, Cerio ED, Diaz-Guemes I, Sanchez FM. Consistent phosphenes generated by electrical microstimulation of the visual thalamus. An experimental approach for thalamic visual neuroprostheses. Front Neurosci. 2011;5:84.

27. Urbanski M, Coubard OA, Bourlon C. Visualizing the blind brain: brain imaging of visual field defects from early recovery to rehabilitation techniques. Front Integr Neurosci. 2014:8:74.

28. DeSimone K, Viviano JD, Schneider KA. Population receptive field estimation reveals new retinotopic maps in human subcortex. J Neurosci. 2015;35(27):9836-47.

29. Bear MF, Connors BW, Paradiso MA. Neurosciences à la découverte du cerveau: Éditions Pradel. 2007.

30. Hattar S, Kumar M, Park A, Tong P, Tung J, Yau KW, Berson DM, et al. Central projections of melanopsin-expressing retinal ganglion cells in the mouse. J Comp Neurol. 2006;497(3):326-49.

31. Dacey DM, Liao HW, Peterson BB, Robinson FR, Smith VC, Pokorny J, Yau KW, Gamlin PD. et al. Melanopsin-expressing ganglion cells in primate retina signal colour and irradiance and project to the LGN. Nature. 2005;433(7027): 749-54.

32. Estevez ME, Fogerson PM, llardi MC, Borghuis BG, Chan E, Weng S, Auferkorte ON, Demb JB, Berson DM, et al. Form and function of the M4 cell, an intrinsically photosensitive retinal ganglion cell type contributing to geniculocortical vision. J Neurosci. 2012;32(39):13608-20.

33. Storchi R, Milosavljevic N, Eleftheriou CG, Martial FP, Orlowska-Feuer P, Bedford RA, Brown TM, Montemurro MA, Petersen RS, Lucas RJ, et al. Melanopsin-driven increases in maintained activity enhance thalamic visual response reliability across a simulated dawn. Proc Natl Acad Sci U S A. 2015; 112(42):E5734-5743.

34. Provencio I, Warther DM. Melanopsin, the photopigment of intrinsically photosensitive retinal ganglion cells. WIREs Membr Transp Signal. 2012;1: 228-237.

35. Hatori M, Le H, Vollmers C, Keding SR, Tanaka N, Buch T, Waisman A, Schmedt C, Jegla T, Panda S, et al. Inducible ablation of melanopsinexpressing retinal ganglion cells reveals their central role in non-image forming visual responses. PLoS One. 2008;3(6):e2451.

36. McNeill DS, Sheely CJ, Ecker JL, Badea TC, Morhardt D, Guido W, Hattar S, et al. Development of melanopsin-based irradiance detecting circuitry. Neural Dev. 2011;6:8

37. Lupi D, Oster H, Thompson S, Foster RG. The acute light-induction of sleep is mediated by OPN4-based photoreception. Nat Neurosci. 2008;11(9):1068-73.

38. Tsai JW, Hannibal J, Hagiwara G, Colas D, Ruppert E, Ruby NF, Heller HC, Franken $\mathrm{P}$, Bourgin $\mathrm{P}$, et al. Melanopsin as a sleep modulator: circadian gating of the direct effects of light on sleep and altered sleep homeostasis in Opn4 (-/-) mice. PLoS Biol. 2009;7(6):e1000125. 
39. Ralph MR, Foster RG, Davis FC, Menaker M. Transplanted suprachiasmatic nucleus determines circadian period. Science. 1990;247(4945):975-8.

40. Morin LP. Neuroanatomy of the extended circadian rhythm system. Exp Neurol. 2013:243:4-20.

41. Teclemariam-Mesbah R, Ter Horst GJ, Postema F, Wortel J, Buijs RM. Anatomical demonstration of the suprachiasmatic nucleus-pineal pathway. J Comp Neurol. 1999;406(2):171-82.

42. Markwell EL, Feigl B, Zele AJ. Intrinsically photosensitive melanopsin retinal ganglion cell contributions to the pupillary light reflex and circadian rhythm. Clin Exp Optom. 2010;93(3):137-49.

43. Chou TC, Scammell TE, Gooley JJ, Gaus SE, Saper CB, Lu J. Critical role of dorsomedial hypothalamic nucleus in a wide range of behavioral circadian rhythms. J Neurosci. 2003;23(33):10691-702.

44. Sakurai T. The neural circuit of orexin (hypocretin): maintaining sleep and wakefulness. Nat Rev Neurosci. 2007;8(3):171-81.

45. Seeley WW, Menon V, Schatzberg AF, Keller J, Glover GH, Kenna H, Reiss AL, Greicius MD, et al. Dissociable intrinsic connectivity networks for salience processing and executive control. J Neurosci. 2007;27(9):2349-56.

46. Allen AE, Brown TM, Lucas RJ. A distinct contribution of short-wavelengthsensitive cones to light-evoked activity in the mouse pretectal olivary nucleus. J Neurosci. 2011;31(46):16833-43.

47. Gooley JJ, Ho Mien I, St Hilaire MA, Yeo SC, Chua EC, van Reen E, Hanley CJ, Hull JT, Czeisler CA, Lockley SW, et al. Melanopsin and rod-cone photoreceptors play different roles in mediating pupillary light responses during exposure to continuous light in humans. J Neurosci. 2012;32(41): 14242-53.

48. McDougal DH, Gamlin PD. The influence of intrinsically-photosensitive retinal ganglion cells on the spectral sensitivity and response dynamics of the human pupillary light reflex. Vis Res. 2010;50(1):72-87.

49. Szkudlarek HJ, Orlowska P, Lewandowski MH. Light-induced responses of slow oscillatory neurons of the rat olivary pretectal nucleus. PLoS One. 2012; 7(3):e33083.

50. Tsujimura S, Ukai K, Ohama D, Nuruki A, Yunokuchi K. Contribution of human melanopsin retinal ganglion cells to steady-state pupil responses. Proc Biol Sci. 2010;277(1693):2485-92.

51. Walmsley L, Hanna L, Mouland J, Martial F, West A, Smedley AR, Bechtold DA, Webb AR, Lucas RJ, Brown TM, et al. Colour as a signal for entraining the mammalian circadian clock. PLoS Biol. 2015;13(4):e1002127.

52. Chen SK, Badea TC and Hattar S. Photoentrainment and pupillary light reflex are mediated by distinct populations of ipRGCs. Nature. 2011:476:92-95.

53. Lockley SW, Evans EE, Scheer FA, Brainard GC, Czeisler CA, Aeschbach D. Short-wavelength sensitivity for the direct effects of light on alertness, vigilance, and the waking electroencephalogram in humans. Sleep. 2006;29(2):161-8.

54. Lockley SW, Brainard GC, Czeisler CA. High sensitivity of the human circadian melatonin rhythm to resetting by short wavelength light. J Clin Endocrinol Metab. 2003;88(9):4502-5.

55. Cajochen C, Munch M, Kobialka S, Krauchi K, Steiner R, Oelhafen P, Orgul S, Wirz-Justice A, et al. High sensitivity of human melatonin, alertness, thermoregulation, and heart rate to short wavelength light. J Clin Endocrinol Metab. 2005;90(3):1311-6.

56. Vandewalle G, Schwartz S, Grandjean D, Wuillaume C, Balteau E, Degueldre C, Schabus M, Phillips C, Luxe A, Dijk DJ, Maquet P, et al. Spectral quality of light modulates emotional brain responses in humans. Proc Natl Acad Sci U S A. 2010;107(45):19549-54.

57. Vandewalle G, Archer SN, Wuillaume C, Balteau E, Degueldre C, Luxen A, Dijk DJ, Maquet $P$, et al. Effects of light on cognitive brain responses depend on circadian phase and sleep homeostasis. J Biol Rhythm. 2011; 26(3):249-59.

58. Brainard GC, Hanifin JP, Greeson JM, Byrne B, Glickman G, Gerner E, Rollag $M D$, et al. Action spectrum for melatonin regulation in humans: evidence for a novel circadian photoreceptor. J Neurosci. 2001;21(16):6405-12.

59. Mure LS, Cornut PL, Rieux C, Drouyer E, Denis P, Gronfier C, Cooperet HM, et al. Melanopsin bistability: a fly's eye technology in the human retina. PLoS One. 2009;4(6):e5991.

60. Chellappa SL, Steiner R, Oelhafen P, Lang D, Gotz T, Krebs J, Cajochen C, et al. Acute exposure to evening blue-enriched light impacts on human sleep. J Sleep Res. 2013;22(5):573-80.

61. Viola AU, James LM, Schlangen LJ, Dijk DJ. Blue-enriched white light in the workplace improves self-reported alertness, performance and sleep quality. Scand J Work Environ Health. 2008;34(4):297-306.
62. Revell VL, Arendt J, Fogg LF, Skene DJ. Alerting effects of light are sensitive to very short wavelengths. Neurosci Lett. 2006;399(1-2):96-100.

63. Chellappa SL, Viola AU, Schmidt C, Bachmann V, Gabel V, Maire M, Reichert CF, Valomon A, Gotz T, Landolt HP, Cajochen C, et al. Human melatonin and alerting response to blue-enriched light depend on a polymorphism in the clock gene PER3. J Clin Endocrinol Metab. 2012;97(3):E433-437.

64. Chellappa SL, Gordijn MC, Cajochen C. Can light make us bright? Effects of light on cognition and sleep. Prog Brain Res. 2011;190:119-33.

65. Okamoto Y, Nakagawa S. Effects of daytime light exposure on cognitive brain activity as measured by the ERP P300. Physiol Behav. 2015;138:313-8.

66. Vandewalle G, Schmidt C, Albouy G, Sterpenich V, Darsaud A, Rauchs G, Berken PY, Balteau E, Degueldre C, Luxen A, Maquet P, Dijk DJ, et al. Brain responses to violet, blue, and green monochromatic light exposures in humans: prominent role of blue light and the brainstem. PLoS One. 2007:2(11):e1247.

67. Vandewalle G, Gais S, Schabus M, Balteau E, Carrier J, Darsaud A, Sterpenich V, Albouy G, Dijk DJ, Maquet P, et al. Wavelengthdependent modulation of brain responses to a working memory task by daytime light exposure. Cereb Cortex. 2007;17(12):2788-95.

68. Vandewalle $\mathrm{G}$. The stimulating impact of light on brain cognition function. Med Sci. 2014:30(10):902-9.

69. Vandewalle G, Collignon O, Hull JT, Daneault V, Albouy G, Lepore F, Phillips C, Doyon J, Czeisler CA, Dumont M, Lockley SW, Carrier J, et al. Blue light stimulates cognitive brain activity in visually blind individuals. J Cogn Neurosci. 2013;25(12):2072-85.

70. Vandewalle G, Hebert M, Beaulieu C, Richard L, Daneault V, Garon ML, Leblanc J, Grandjean D, Maquet P, Schwartz S, Dumont M, Doyon J, Carrier J, et al. Abnormal hypothalamic response to light in seasonal affective disorder. Biol Psychiatry. 2011;70(10):954-61.

71. Vandewalle G, Balteau E, Phillips C, Degueldre C, Moreau V, Sterpenich V, Albouy G, Darsaud A, Desseilles M, Dang-Vu TT, Peigneux P, Luxen A, Dijk DJ, et al. Daytime light exposure dynamically enhances brain responses. Curr Biol. 2006;16(16):1616-21.

72. Perrin F, Peigneux $P$, Fuchs S, Verhaeghe S, Laureys S, Middleton B, Degueldre C, Del Fiore G, Vandewalle G, Balteau E, Poirrier R, Moreau V, Luxen $\mathrm{A}$, et al. Nonvisual responses to light exposure in the human brain during the circadian night. Curr Biol. 2004;14(20):1842-6.

73. Matsuyama T, Yamashita T, Imamoto Y, Shichida Y. Photochemical properties of mammalian melanopsin. Biochemistry. 2012;51(27):5454-62.

74. Mure LS, Rieux C, Hattar S, Cooper HM. Melanopsin-dependent nonvisual responses: evidence for photopigment bistability in vivo. J Biol Rhythm. 2007:22(5):411-24.

75. Chellappa SL, Ly JQ, Meyer C, Balteau E, Degueldre C, Luxen A, Phillips C, Cooper HM, Vandewalle G. Photic memory for executive brain responses. PNAS. 2014; 111(16):6087-91.

76. Gaggioni G, Maquet P, Schmidt C, Dijk DJ, Vandewalle G. Neuroimaging, cognition, light and circadian rhythms. Front Syst Neurosci. 2014;8:126.

77. Herljevic M, Middleton B, Thapan K, Skene DJ. Light-induced melatonin suppression: age-related reduction in response to short wavelength light. Exp Gerontol. 2005;40(3):237-42.

78. Sletten TL, Revell VL, Middleton B, Lederle KA, Skene DJ. Age-related changes in acute and phase-advancing responses to monochromatic light. J Biol Rhythm. 2009;24(1):73-84.

79. Jud C, Chappuis S, Revell VL, Sletten TL, Saaltink DJ, Cajochen C, Skene DJ, Albrecht U. Age-dependent alterations in human PER2 levels after early morning blue light exposure. Chronobiol Int. 2009;26(7):1462-9.

80. Benloucif S, Green K, L'Hermite-Baleriaux M, Weintraub S, Wolfe LF, Zee PC. Responsiveness of the aging circadian clock to light. Neurobiol Aging. 2006; 27(12):1870-9.

81. Nathan PJ, Burrows GD, Norman TR. The effect of age and pre-light melatonin concentration on the melatonin sensitivity to dim light. Int Clin Psychopharmacol. 1999;14(3):189-92.

82. Klerman EB, Duffy JF, Dijk DJ, Czeisler CA. Circadian phase resetting in older people by ocular bright light exposure. J Investig Med. 2001;49(1):30-40.

83. Samuels ER, Szabadi E. Functional neuroanatomy of the noradrenergic locus coeruleus: its roles in the regulation of arousal and autonomic function part II: physiological and pharmacological manipulations and pathological alterations of locus coeruleus activity in humans. Curr Neuropharmacol. 2008:6(3):254-85.

84. Charman WN. Age, lens transmittance, and the possible effects of light on melatonin suppression. Ophthalmic Physiol Opt. 2003;23(2):181-7. 
85. Hammond Jr BR, Nanez JE, Fair C, Snodderly DM. Iris color and age-related changes in lens optical density. Ophthalmic Physiol Opt. 2000;20(5):381-6.

86. Kessel L, Lundeman JH, Herbst K, Andersen TV, Larsen M. Age-related changes in the transmission properties of the human lens and their relevance to circadian entrainment. J Cataract Refract Surg. 2010;36(2):308-12.

87. Turner PL, Mainster MA. Circadian photoreception: ageing and the eye's important role in systemic health. Br J Ophthalmol. 2008;92(11):1439-44.

88. Farajnia S, Michel S, Deboer T, van der Leest HT, Houben T, Rohling JH, Ramkisoensing $\mathrm{JH}$, Yasenkov R, Meijer JH. Evidence for neuronal desynchrony in the aged suprachiasmatic nucleus clock. J Neurosci. 2012; 32(17):5891-9.

89. Kondratova AA, Kondratov RV. The circadian clock and pathology of the ageing brain. Nat Rev Neurosci. 2012;13(5):325-35.

90. Asai M, Yoshinobu Y, Kaneko S, Mori A, Nikaido T, Moriya T, Akiyama M, Shibata S. Circadian profile of Per gene mRNA expression in the suprachiasmatic nucleus, paraventricular nucleus, and pineal body of aged rats. J Neurosci Res. 2001;66(6):1133-9.

91. Davidson AJ, Yamazaki S, Arble DM, Menaker M, Block GD. Resetting of central and peripheral circadian oscillators in aged rats. Neurobiol Aging. 2008;29(3):471-7.

92. Kolker DE, Fukuyama H, Huang DS, Takahashi JS, Horton TH, Turek FW. Aging alters circadian and light-induced expression of clock genes in golden hamsters. J Biol Rhythm. 2003;18(2):159-69.

93. Sitzmann BD, Lemos DR, Ottinger MA, Urbanski HF. Effects of age on clock gene expression in the rhesus macaque pituitary gland. Neurobiol Aging. 2010;31(4):696-705.

94. Claustrat F, Fournier I, Geelen G, Brun J, Corman B, Claustrat B. Aging and circadian clock gene expression in peripheral tissues in rats. Pathol Biol. 2005;53(5):257-60.

95. Gibson EM, Williams 3rd WP, Kriegsfeld LJ. Aging in the circadian system: considerations for health, disease prevention and longevity. Exp Gerontol. 2009;44(1-2):51-6.

96. Kawakami F, Okamura H, Tamada Y, Maebayashi Y, Fukui K, Ibata Y. Loss of day-night differences in VIP mRNA levels in the suprachiasmatic nucleus of aged rats. Neurosci Lett. 1997;222(2):99-102.

97. Kawaguchi C, Isojima Y, Shintani N, Hatanaka M, Guo X, Okumura N, Nagai K, Hashimoto H, Baba, A. PACAP-deficient mice exhibit light parameterdependent abnormalities on nonvisual photoreception and early activity onset. PLoS One. 2010;5(2):e9286.

98. Roozendaal B, van Gool WA, Swaab DF, Hoogendijk JE, Mirmiran M. Changes in vasopressin cells of the rat suprachiasmatic nucleus with aging. Brain Res. 1987;409(2):259-64.

99. Hofman MA, Swaab DF. Alterations in circadian rhythmicity of the vasopressin-producing neurons of the human suprachiasmatic nucleus (SCN) with aging. Brain Res. 1994;651(1-2):134-42.

100. Hofman MA. The human circadian clock and aging. Chronobiol Int. 2000; 17(3):245-59.

101. Aujard F, Cayetanot F, Bentivoglio M, Perret M. Age-related effects on the biological clock and its behavioral output in a primate. Chronobiol Int. 2006; 23(1-2):451-60.

102. Cayetanot F, Bentivoglio M, Aujard F. Arginine-vasopressin and vasointestinal polypeptide rhythms in the suprachiasmatic nucleus of the mouse lemur reveal aging-related alterations of circadian pacemaker neurons in a non-human primate. Eur J Neurosci. 2005;22(4):902-10.

103. Hofman MA. Circadian oscillations of neuropeptide expression in the human biological clock. J Comp Physiol A Neuroethol Sens Neural Behav Physiol. 2003;189(11):823-31.

104. Long $X$, Liao W, Jiang C, Liang D, Qiu B, Zhang L. Healthy aging: an automatic analysis of global and regional morphological alterations of human brain. Acad Radiol. 2012;19(7):785-93.

105. Peters $A$. The effects of normal aging on myelin and nerve fibers: a review. J Neurocytol. 2002;31(8-9):581-93.

106. Guttmann CR, Jolesz FA, Kikinis R, Killiany RJ, Moss MB, Sandor T, Albert MS. White matter changes with normal aging. Neurology. 1998;50(4):972-8.

107. Walhovd KB, Fjell AM, Reinvang I, Lundervold A, Dale AM, Eilertsen DE, Quinn BT, Salat D, Makris N, Fischl B. Effects of age on volumes of cortex, white matter and subcortical structures. Neurobiol Aging. 2005;26(9):1261-70. discussion 1275-1268.

108. Samuels ER, Szabadi E. Functional neuroanatomy of the noradrenergic locus coeruleus: its roles in the regulation of arousal and autonomic function part I: principles of functional organisation. Curr Neuropharmacol. 2008;6(3):235-53.

109. Deng XH, Bertini G, Palomba M, Xu YZ, Bonaconsa M, Nygard M, Bentivoglio M. Glial transcripts and immune-challenged glia in the suprachiasmatic nucleus of young and aged mice. Chronobiol Int. 2010;27(4):742-67.

110. Fotiou DF, Brozou CG, Tsiptsios DJ, Fotiou A, Kabitsi A, Nakou M, Giantselidis C, Goula A. Effect of age on pupillary light reflex: evaluation of pupil mobility for clinical practice and research. Electromyogr Clin Neurophysiol. 2007:47(1):11-22.

111. Freund PR, Watson J, Gilmour GS, Gaillard F, Sauve Y. Differential changes in retina function with normal aging in humans. Doc Ophthalmol. 2011; 122(3):177-90.

112. Hebert M, Beattie CW, Tam EM, Yatham LN, Lam RW. Electroretinography in patients with winter seasonal affective disorder. Psychiatry Res. 2004; 127(1-2):27-34

113. Sturr JF, Zhang L, Taub HA, Hannon DJ, Jackowski MM. Psychophysical evidence for losses in rod sensitivity in the aging visual system. Vis Res. 1997;37(4):475-81.

114. Bitsios P, Prettyman R, Szabadi E. Changes in autonomic function with age: a study of pupillary kinetics in healthy young and old people. Age Ageing. 1996;25(6):432-8.

115. Winn B, Whitaker D, Elliott DB, Phillips NJ. Factors affecting light-adapted pupil size in normal human subjects. Invest Ophthalmol Vis Sci. 1994; 35(3):1132-7

116. Daneault V, Vandewalle G, Hebert M, Teikari P, Mure LS, Doyon J, Gronfier C Cooper HM, Dumont M, Carrier J. Does pupil constriction under blue and green monochromatic light exposure change with age? J Biol Rhythm. 2012;27(3):257-64

117. Daneault V, Hebert M, Albouy G, Doyon J, Dumont M, Carrier J, Vandewalle $\mathrm{G}$. Aging reduces the stimulating effect of blue light on cognitive brain functions. Sleep. 2014;37(1):85-96.

118. Pickard GE, Sollars PJ. Intrinsically photosensitive retinal ganglion cells. Sci China Life Sci. 2010;53(1):58-67.

119. Pickard GE, Baver SB, Ogilvie MD, Sollars PJ. Light-induced fos expression in intrinsically photosensitive retinal ganglion cells in melanopsin knockout (opn4) mice. PLoS One. 2009;4(3):e4984

120. LeGates TA, Fernandez DC, Hattar S. Light as a central modulator of circadian rhythms, sleep and affect. Nat Rev Neurosci. 2014;15(7):443-54.

121. Butler MP, Silver R. Divergent photic thresholds in the non-image-forming visual system: entrainment, masking and pupillary light reflex. Proc Biol Sci. 2011;278(1706):745-50.

122. Hut RA, Oklejewicz M, Rieux C, Cooper HM. Photic sensitivity ranges of hamster pupillary and circadian phase responses do not overlap. J Biol Rhythm. 2008;23(1):37-48.

123. Owen AM, McMillan KM, Laird AR, Bullmore E. N-back working memory paradigm: a meta-analysis of normative functional neuroimaging studies. Hum Brain Mapp. 2005;25(1):46-59.

124. Luo AH, Aston-Jones G. Circuit projection from suprachiasmatic nucleus to ventral tegmental area: a novel circadian output pathway. Eur J Neurosci. 2009;29(4):748-60

125. Stein JL, Wiedholz LM, Bassett DS, Weinberger DR, Zink CF, Mattay VS, Meyer-Lindenberg A. A validated network of effective amygdala connectivity. Neurolmage. 2007;36(3):736-45.

126. Menon V, Uddin LQ. Saliency, switching, attention and control: a network model of insula function. Brain Struct Funct. 2010;214(5-6):655-67.

127. Koechlin E, Hyafil A. Anterior prefrontal function and the limits of human decision-making. Science. 2007;318(5850):594-8.

128. Kessler BA, Stanley EM, Frederick-Duus D, Fadel J. Age-related loss of orexin/ hypocretin neurons. Neuroscience. 2011;178:82-8.

129. Kilduff TS, Peyron C. The hypocretin/orexin ligand-receptor system: implications for sleep and sleep disorders. Trends Neurosci. 2000;23(8): 359-65.

130. Shan L, Dauvilliers Y, Siegel JM. Interactions of the histamine and hypocretin systems in CNS disorders. Nat Rev Neurol. 2015;11(7):401-13.

131. Sutcliffe JG, de Lecea L. The hypocretins: excitatory neuromodulatory peptides for multiple homeostatic systems, including sleep and feeding. J Neurosci Res. 2000;62(2):161-8.

132. Ebrahim 1O, Howard RS, Kopelman MD, Sharief MK, Williams AJ. The hypocretin/orexin system. J R Soc Med. 2002;95(5):227-30.

133. Di Giovanni G, Di Matteo V, Pierucci M, Esposito E. Serotonin-dopamine interaction: electrophysiological evidence. Prog Brain Res. 2008;172:45-71. 
134. Eppinger B, Hammerer D, Li SC. Neuromodulation of reward-based learning and decision making in human aging. Ann N Y Acad Sci. 2011;1235:1-17.

135. Rao V, Spiro JR, Samus QM, Rosenblatt A, Steele C, Baker A, Harper M, Brandt J, Mayer L, Rabins PV, Lyketsos CG. Sleep disturbances in the elderly residing in assisted living: findings from the Maryland Assisted Living Study. Int J Geriatr Psychiatry. 2005;20(10):956-66.

136. Foley D, Monjan A, Masaki K, Ross W, Havlik R, White L, Launer L. Daytime sleepiness is associated with 3-year incident dementia and cognitive decline in older Japanese-American men. J Am Geriatr Soc. 2001;49(12):1628-32.

137. Merlino G, Piani A, Gigli GL, Cancelli I, Rinaldi A, Baroselli A, Serafini A, Zanchettin B, Valente M. Daytime sleepiness is associated with dementia and cognitive decline in older Italian adults: a population-based study. Sleep Med. 2010;11(4):372-7.

138. Keage HA, Banks S, Yang KL, Morgan K, Brayne C, Matthews FE. What sleep characteristics predict cognitive decline in the elderly? Sleep Med. 2012; 13(7):886-92.

139. Elwood PC, Bayer AJ, Fish M, Pickering J, Mitchell C, Gallacher JE. Sleep disturbance and daytime sleepiness predict vascular dementia. J Epidemiol Community Health. 2011;65(9):820-4.

140. Abbott RD, Ross GW, White LR, Tanner CM, Masaki KH, Nelson JS, Curb JD, Petrovitch $\mathrm{H}$. Excessive daytime sleepiness and subsequent development of Parkinson disease. Neurology. 2005;65(9):1442-6.

141. Ohayon MM, Vecchierini MF. Normative sleep data, cognitive function and daily living activities in older adults in the community. Sleep. 2005;28(8):981-9.

142. Lee JH, Bliwise DL, Ansari FP, Goldstein FC, Cellar JS, Lah JJ, Levey Al. Daytime sleepiness and functional impairment in Alzheimer disease. Am J Geriatr Psychiatr. 2007;15(7):620-6.

143. Shin HY, Han HJ, Shin DJ, Park HM, Lee YB, Park KH. Sleep problems associated with behavioral and psychological symptoms as well as cognitive functions in Alzheimer's disease. J Clin Neurol. 2014;10(3):203-9.

144. Willis GL, Moore C, Armstrong SM. A historical justification for and retrospective analysis of the systematic application of light therapy in Parkinson's disease. Rev Neurosci. 2012;23(2):199-226.

145. Yamadera $H$, Ito T, Suzuki H, Asayama K, Ito R, Endo S. Effects of bright light on cognitive and sleep-wake (circadian) rhythm disturbances in Alzheimertype dementia. Psychiatry Clin Neurosci. 2000;54(3):352-3.

146. Ito T, Yamadera H, Ito R, Endo S. Effects of bright light on cognitive disturbances in Alzheimer-type dementia. Nihon Ika Daigaku Zasshi. 1999;66(4):229-38.

147. Nowak L, Davis J. Qualitative analysis of therapeutic light effects on global function in Alzheimer's disease. West J Nurs Res. 2011;33(7):933-52.

148. Cajochen C, Chellappa S, Schmidt C. What keeps us awake? The role of clocks and hourglasses, light, and melatonin. Int Rev Neurobiol. 2010;93:57-90.

149. Higuchi S, Hida A, Tsujimura S, Mishima K, Yasukouchi A, Lee SI, Kinjyo Y, Miyahira M. Melanopsin gene polymorphism 1394T is associated with pupillary light responses in a dose-dependent manner. PLoS One. 2013;8(3): e60310

150. Lee SI, Hida A, Tsujimura S, Morita T, Mishima K, Higuchi S. Association between melanopsin gene polymorphism (1394T) and pupillary light reflex is dependent on light wavelength. J Physiol Anthropol. 2013;32:16.

\section{Submit your next manuscript to BioMed Central and we will help you at every step:}

- We accept pre-submission inquiries

- Our selector tool helps you to find the most relevant journal

- We provide round the clock customer support

- Convenient online submission

- Thorough peer review

- Inclusion in PubMed and all major indexing services

- Maximum visibility for your research

Submit your manuscript at www.biomedcentral.com/submit
C Biomed Central 